\title{
Correction to: The Role of Laparoscopic Surgery in Localized Pancreatic Neuroendocrine Tumours
}

Valentina Ferraro, $M D^{1, *}$

Michele Tedeschi, MD, PhD ${ }^{1}$

Letizia Laera, $M D^{2}$

Michele Ammendola, MD, PhD ${ }^{3}$

Umberto Riccelli, $M D^{4}$

Nicola Silvestris, $M D, P h D^{5}$

Alba Fiorentino, $M D, P h D^{6}$

Giammarco Surico, $M D^{2}$

Riccardo Inchingolo, $M D^{7}$

Francesco Decembrino, $M D^{8}$

Nicola de Angelis, MD, PhD ${ }^{9}$

Riccardo Memeo, $M D, P h D^{1}$

\footnotetext{
Address

${ }^{*}, 1$ Hepato-Pancreato-Biliary Surgery Unit, Miulli Hospital, Acquaviva delle Fonti, Bari, Italy

Email: ferrarov.v@libero.it

${ }^{2}$ Medical Oncology Unit, Miulli Hospital, Acquaviva delle Fonti, Bari, Italy

${ }^{3}$ Department of Health Sciences, General Surgery, Magna Græcia University, Medicine School of Germaneto, Catanzaro, Italy

"Department of Reconstructive Surgery, "Pugliese Ciaccio" Hospital, Catanzaro, Italy ${ }^{5}$ Medical Oncology Unit, IRCCS Cancer Institute "Giovanni Paolo II", Bari, Italy ${ }^{6}$ Radiotherapy Unit, Miulli Hospital, Acquaviva delle Fonti, Bari, Italy

${ }^{7}$ Interventional Radiology Unit, Miulli Hospital, Acquaviva delle Fonti, Bari, Italy

${ }^{8}$ Gastroenterology and Endoscopy Unit, Miulli Hospital, Acquaviva delle Fonti, Bari, Italy

${ }^{9}$ Minimally invasive and Robotic Gastrointestinal Surgery, Acquaviva delle Fonti, Bari, Italy
}

Published online: 18 March 2021

(C) Springer Science+Business Media, LLC, part of Springer Nature 2021 
Correction to: Curr. Treat. Options in Oncol. 22, 27 (2021)

https://doi.org/10.1007/s11864-021-00824-5

The original version of this article unfortunately contained a mistake. The family name of the ninth author, Riccardo Inchingolo, was misspelled as Inchingololo.

The original article has been corrected.

\section{Publisher's note}

Springer Nature remains neutral with regard to jurisdictional claims in published maps and institutional affiliations. 